\title{
Exploring the Potential of Mobile Crowdsourcing in the Sharing of Information on Items Prices
}

\author{
Hazleen Aris and Marina Md Din \\ College of Computer Science and Information Technology \\ Universiti Tenaga Nasional, \\ Kajang, Malaysia \\ Email: hazleen@uniten.edu.my
}

\begin{abstract}
This article presents the result of a survey performed to identify the potential of using mobile crowdsourcing as means to exchange information on the prices of household items at local stores from the consumers point of view. The potential was identified from four perspectives; mobile devices capability, internet usage pattern, supporting infrastructure and readiness towards information sharing. Survey questionnaires comprising 18 quantitative questions were distributed to 138 respondents in the forms of hardcopy and online softcopy over a one month period in May 2014. Collected data were analysed using descriptive statistics and correlation analysis methods. Findings from the analyses showed that the potential of using mobile crowdsourcing in sharing information of item prices is high as seen from the perspectives of the mobile devices capability and supporting infrastructure. Internet usage pattern of the consumers as well as their attitude towards information sharing are also in support of the potential. To the best of our knowledge, this is the first study that gathered statistical data on the potential of using mobile crowdsourcing for the sharing of information on items prices. Potential is usually assumed based on informal observation on the prevalent of mobile devices and their widespread use, and are not supported by empirical data. It is of value to the broader research communities who are currently engaged in mobile crowdsourcing research for consumers benefits.
\end{abstract}

Index Terms-Mobile crowdsourcing; Price comparison; Crowdsourcing potential; Crowdsourcing survey

\section{INTRODUCTION}

Shopping, in particular groceries and household items shopping, is already part and parcel of modern living. Supermarkets and grocery stores are now the main sources where people obtain their necessities from. In Malaysia for example, it was reported that the average monthly expenditure per household in 2010 was RM2190 per month, which is equivalent to RM26,280 a year. In the UK, households spent an average of $£ 489$ a week in 2012 , amounting to $£ 23,472$ a year. Thus, it can be seen that household expenditures contributed significantly to the overall expenses. Any increment or reduction in household expenses will therefore significantly affect the costs of living. In relation to this, the ever increasing price of goods has become a phenomenon that is near to the heart of many people. This phenomenon is unstoppable and nothing much can be done to curb the price from keep on hiking. It is a global issue and the increase everywhere. In Malaysia, an increase of $12.1 \%$ in five years time between 2004/2005 and 2009/2010 was recorded from the national census done every five year by the Department of Statistics Malaysia [1]. A report on consumer expenditure survey by US Bureau of Labor Statistics [31] also showed an increase of 3.5\% in consumer spending in 2012, and this was the second consecutive year that expenditures increased. In Singapore, the consumer price index (CPI) for general household rose by $4.6 \%$ for the full year of 2012 and by $2.4 \%$ for the full year of 2013 [3]. These are just some examples that we had gathered and it is believed that the situations in other countries are about the same.

Given the facts and figures above, it seems like the increase is unpreventable and we just have to 'live' with this increase in the cost of living. We should therefore live with it 'wisely' by taking appropriate measures to alleviate its effects. In [8], the following three approaches that can help in moderating the impact of price hike were discussed.

- By raising the standard of living of the citizens.

- By reducing the prices of household items, followed by close monitoring and surveillance.

- By providing the means to facilitate consumers to perform selective purchase of household items.

In the article, it was concluded and justified that the third approach was seen as the most practical in the sense that it requires minimal intervention from the authority and hence, can be almost immediately implemented if the technology is available. It is also in line with the urge for the consumers to play bigger role in determining the prices of items [36]. Through this approach, the power of consumers is leveraged by encouraging them to be more selective in purchasing the household items. Being selective means, rather than just buying an item the moment they see it, consumers should spend some extra effort to compare the prices of that item at the nearby stores to see which store can give them the lowest price. This extra effort, however, has to be negligible in order to make this approach favourable. Our quick survey into the market proved the feasibility of this approach. Table I shows the prices of a selection of common household items at three different stores. As can be seen from the table, the difference in items prices can be significant when the prices are totalled up.

Traditional way of comparing prices of items from one store to another requires the customer to visit each store, which is time consuming and troublesome. Thus, the main challenge is to reduce significantly the time and effort needed to perform 
TABLE I: Prices of selected items at three different stores

\begin{tabular}{lrrr}
\hline & \multicolumn{3}{c}{ Price (RM) } \\
\cline { 2 - 4 } Item & Store A & Store B & Store C \\
\hline Rambutan Thai White Rice (10kg) & 30.99 & 26.99 & 27.99 \\
Jacobs Cream Cracker (750g) & 10.49 & 10.99 & 13.99 \\
Ayam A1 Fried Chicken Crispy (850g) & 7.99 & 10.35 & 10.50 \\
Naturel Olive Oil Extra Virgin (2kg) & 18.99 & 14.99 & 19.50 \\
Drypers Soft New Born (64 pcs) & 31.99 & 31.90 & 31.59 \\
Milo Protomalt Soft Pack (1kg) & 16.49 & 16.75 & 17.99 \\
Nutriplus Fresh Egg Organic Selenium & 5.49 & 5.29 & 4.99 \\
M Size (10 pcs) & & & \\
\hline Total & 122.43 & 117.26 & 126.55 \\
\hline
\end{tabular}

the comparison. Consumers should be able to perform the prices comparison without leaving the comfort of their house. Mobile crowdsourcing was identified as a viable solution to address the challenge [9], thanks to the widespread availability and accessibility of mobile devices nowadays. Through mobile crowdsourcing, consumers from different locations can contribute information on prices of items at the local stores that they visited, to a mobile application that will compile and process the information for use by other consumers. Existing literature shows that theoretically, mobile crowdsourcing has a good potential to be used in information gathering of this kind. However, its potential from the practical point of view needs to be explored too. This research therefore aims at exploring the potential of using mobile crowdsourcing in the sharing of information on prices of items from the practical point of view, that is, from the perspective of the consumers. Section II provides the theoretical background of the research that leads to the justification on the need for this research. Section III explains about the method applied, which was the survey. Section IV presents the results and analyses performed on the results. Section V discusses the findings followed by section VI on threats to validity. Section VII concludes the article.

\section{BACKGROUND}

Crowdsourcing is one of the many new concepts that have emerged resulting from the advancement of the information and communication technology (ICT). Crowdsourcing was first introduced in 2006 to mean the act of taking a job traditionally performed by a designated agent, usually an employee, and outsourcing it to an undefined, generally large group of people, i.e. the crowd, in the form of open call [25]. The open calls are usually made through the internet. In crowdsourcing, at least three components exist; organiser, task and a group of solvers. Organiser is the person or company who initiates an assignment or a job. A task is the assignment being offered to be solved and a group of solvers is the participating crowd who is going to solve the given task. The following are the characteristics of crowdsourcing [17].

- Clearly defined crowd

- Task with clear goal

- Clear recompense received (by the crowd)

- Clearly defined crowdsourcer (organiser)

- Clear compensation received (by the crowdsourcer)

- Online assignment and participation of tasks
- Uses open call

- Uses internet

The term mobile crowdsourcing is used in [33] to refer to a particular form of crowdsourcing where the task is made available through mobile devices and the solutions are also submitted through mobile devices. This adds the ninth characteristic of mobile crowdsourcing, which is, uses mobile devices [9].

\section{A. Benefits of crowdsourcing}

The philosophy behind crowdsourcing is the involvement of the community to assist in solving clearly defined problems. Usually, these are the kinds of task that could not have been accomplished by the organiser, most probably due to the expensive cost, time constraint, too routine or requirement of rare knowledge and skills [38]. Crowdsourcing has been used in many domains in order to harness the power and wisdom of the crowd, such as in business and marketing [13][38], sociology [39][24][30], medicine and health [18][39][10][23], environmental sciences [22][21][19], as well as research and development [37][4]. These existing crowdsourcing applications can be generally viewed as commercial crowdsourcing and non-profit crowdsourcing [29].

In commercial crowdsourcing, getting a task done at a cheaper price is amongst the reasons for crowdsourcing. With the increasing availability and affordability of mobile devices such as smart phones, mobile crowdsourcing has gained increasing popularity amongst production-based companies and many have even benefitted from it. Through crowdsourcing, a problem can be explored and solved quickly through decomposition of tasks. The task to be done is decomposed and outsourced by the organiser to the crowd, which the latter submit the best solutions back to the organiser [26]. Crowdsourcing is cheaper because payment is made only for the chosen solution and may even be substituted with other kind of compensation like a small token or prize [16]. Crowdsourcing enables the products to get into the market faster too [38]. Through crowdsourcing, an organisation can tap into a wider range of talents that might be present within its own boundary. Furthermore, selected crowd may have a degree of expertise that is not available within the organisation, who can work to solve more complex issues or tasks. By interacting with the crowd, organisations can gain insight into customers or potential customers preferences that encourage tapping into the intelligence of the crowd in order to address unique, large and critical problems [30]. In addition to these, working with an external group of people can be a source of personal satisfaction too.

Non-profit crowdsourcing is performed by unpaid volunteers for public good [6]. In the non-profit sector, benefits of crowdsourcing are mainly seen in healthcare [27][28] and disaster management [14][20]. In Haiti, in year 2010, the informal sources such as news reports, discussion rooms and Twitter alerted people about cholera outbreak two weeks before the health ministry issued its report. This had managed to give early warning to the public and they could take prevention. 
A similar project, HealthMap Application [11], analyses data that come from the crowd and from the authority such as the ministry of health. This really benefits the community because they are able to detect outbreaks and provide disease surveillance in real-time and hence, precaution and prevention can be prepared earlier. Crowdsourcing can also save lives. Often in our daily lives we heard news of crimes. Application that has ability to report and alert community of any crimes happening in the neighbourhood for example, could help individuals to avoid a particular area for safety reason. Furthermore, rescue mission can reach to the location in a shorter period of time if the function of Help button integrated with the application is activated when someone is under attack [2].

\section{B. Benefits of information sharing}

Information sharing referred to the exchange of data between various organisations, people and technologies. Information sharing is often interchangeably used with knowledge sharing. As far as our review is concerned, there was no clear distinction between these two and this research does not intend to distinguish between the two. The term information sharing will be used throughout this article to refer to the exchange of data between two entities. People have been sharing information since time immemorial and it is done almost naturally using whatever means that the current technologies permit. The advancement of internet and mobile devices has brought information sharing to an unprecedented pace. People share just about anything through social media now including prices of items, if they find them extremely cheap or expensive.

During the primitive era, natural resources such as smoke and sound were used to share information with others. The advent of ICT has changed the way people share information in many ways. It is the spirit of sharing the information with others, be it a good news or otherwise, that has driven people to take advantage of just about all technologies available as long as the information is conveyed. When paper was invented, newspapers were used to disseminate news and other information to the mass. When radio and television were invented, we had the news being broadcast on air. With the diffusion of computers and internet into our daily lives, we have witnessed the birth of so many information portals, which increases the accessibility of information. The latest development in ICT, with the arrival of smartphones and other mobile devices, adds mobility and ubiquity to the existing accessibility where information sharing can be done almost instantly at just about anywhere on earth.

The benefits brought about by information sharing are numerous. A total of 27 benefits of information sharing was listed in [12], which are categorised into four categories; technical, organisational, intra-organisational and environmental. Due to these benefits, information sharing has noticeably been researched in various domains. Supply chain management is an example of such domains. Information sharing in supply chain management is further divided into three types; supply-chainwide information sharing, downstream information sharing and upstream information sharing [21]. It was found that

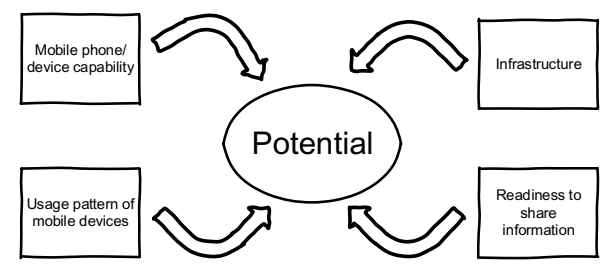

Fig. 1: Four perspectives crowdsourcing potential

the value of information sharing is higher for the upstream firms than for downstream firms under all information sharing types. However, when looking at individual firm, the value of information sharing is higher under downstream information sharing than upstream information sharing. Nevertheless, information sharing research is not limited to manufacturing and supply only. Its application was also being discussed for elementary school [15] and sports [5]. In the field of education, information sharing through social networking sites was being discussed as a way of marketing an institution [7].

Findings from the literature above theoretically confirms the benefits and potential of information sharing. It is expected that the sharing of information on items prices will also gain similar benefits and potential, and this is what we intend to discover from this study. The objective of this research is to examine the potential of using mobile crowdsourcing in the sharing of information on prices of items and the scope of the study is amongst Malaysian consumers. In order to achieve this objective, the following research questions were formulated and addressed by the research.

- What is the current state of mobile devices capabilities?

- What is the pattern of mobile devices amongst the users?

- What is the current state of the existing mobile infrastructure provided?

- What is the users tendency towards sharing information of items prices?

In order to answer the above questions, a survey was performed to identify the potential use of mobile crowdsourcing in the sharing of information on prices of items. The potential was determined from the following four perspectives; capability of mobile devices, pattern of mobile devices usage, supporting infrastructure and readiness to share information with others as shown in Figure 1.

\section{METHOD}

Personal opinion survey [36] was used to obtain the required information from the consumers. Questions in the questionnaire were close-ended and analyses performed were quantitative, as described in more detail below.

\section{A. Questionnaire Design}

After undergoing a number of revisions resulting from a series of discussions with the research team members, the initial version of the questionnaire comprises a total of 19 questions. All questions were close-ended and the choices of answer were either nominal or ordinal. Prior to its actual 
distribution, a pilot test was performed on the initial version of the questionnaire involving ten participants. The purpose of the pilot test was to identify problems with regard to the clarity of the questions asked. During the pilot test, each participant answered the questionnaire in the presence of a research team member. Any issues raised during the questionnaire answering session were recorded by the researcher to be discussed later. As a result of the pilot test, a number of potential problems with regard to the clarity of the questions that might affect the understanding of the participants were identified and rectified. The following is the list of improvements made to the questionnaire.

- Highlight the word main in bold font in the question that asked about the main breadwinner because one participant missed it

- Include elaboration, in brackets, of two terms used, household items and network problem because some participants were unsure about their meanings or scopes. What was meant by household item and what kind of network problem that was referred to.

- Ambiguity of the Likert scales used in some of the questions, which was resolved by using the proposed scales in [34].

- Removal of the last question, question 19 , as it was deemed similar to another question, question 18, by some respondents. Although after relooking into the questions, we still thought that each question would provide different information, we removed the question in respect of the feedback provided by the participants. This was the purpose of the pilot test anyway.

Eventually, the final version of the questionnaire contained 18 questions and was divided into two sections, Section A and Section B. Section A comprised a total of seven questions (Q1 to Q7) that asked about demographics information and information pertaining to household income and expenditure. Questionas in this section collected the following information from the participants.

- Gender (Q1)

- Marital status (Q2)

- Income earner-ship status (Q3)

- Portion (Q4)

- Record keeping of monthly expenditure (Q5)

- Monthly income (Q6) and

- Average monthly expenditure (Q7)

Section B of the questionnaire consisted of 11 questions that were arranged according to the four perspectives that determine the potential of mobile crowdsourcing in information sharing of prices of items shown in Figure 1. Details of the questions are as follows.

- Mobile device capability

- availability (possession) (Q8)

- capability to access the internet (Q9)

- capability to take photo (Q10)

- Pattern of mobile device usage

- mobile device availability during shopping (Q11)
- mobile device accessibility during shopping (Q12)

- hours spent accessing the internet and mobile applications (Q13)

- Supporting infrastructure

- type of mobile plan subscription (Q14)

- network availability with regard to internet accessibility (Q15)

- Readiness to share information with others

- photo sharing through mobile device (Q16)

- current practice in information sharing (Q17)

- willingness to share information $(\mathrm{Q} 18)$

Two versions of the questionnaire were prepared, the hardcopy version and the online version. In the hardcopy version, all of the 18 questions from both sections were designed in such a way that they could all fit into one page, so that potential respondents would not be daunted by the number of questions that they had to answer. A one page questionnaire would be more attractive for them to participate. The online version of the questionnaire was created using Surveyshare.com, an online tool for creating and managing online questionnaires. Surveyshare.com was chosen because of our familiarity with the tool from past experience. Other tools would do just fine. Online questionnaire has advantages over the hardcopy questionnaire with features such as compulsory fields and skipping pattern that were able to avoid human errors. It is important to mention here that the coding system assigned to each question in the questionnaire $(\mathrm{Q} 1, \mathrm{Q} 2$ and et cetera) does not, in any way, relate to the positions of the questions in the questionnaire. The codes were assigned only after the questions were arranged according to four identified perspectives. The actual order of the questions differ in order to adhere to the qualities of good question in [32]. Furthermore, the order of questions in hardcopy questionnaire and online questionnaire also differs slightly because the hardcopy questionnaire has to take into consideration the space constraint. However, the number of questions remain the same.

The goal question metric method [35] was used to design and later analyse the results of the questionnaire. In this method, metrics is defined for each question that explains how result from each question will be analysed towards achieving the objective of the survey. It ensures the exclusion of irrelevant and redundant questions right from the beginning. Table II shows each question in section B of the questionnaire and the respective metrics used to evaluate them. Demographics questions from section $\mathrm{A}$ of the questionnaire were not included.

\section{B. Procedure}

The hardcopy questionnaires were distributed to the visitors who came to our booths in two research exhibitions that we participated, the UNITEN Research Exhibition 2014 (UNIREX 2014) and the International Invention and Technology Exhibition 2014 (ITEX14). The questionnaire answering sessions went smoothly with hardly any question asked, despite answering them at the booth in the presence of the 
TABLE II: GQM table for the questions in the questionnaire

\begin{tabular}{|c|c|c|}
\hline Goal & $\begin{array}{l}\text { Purpose } \\
\text { Issue } \\
\text { Object } \\
\text { Viewpoint }\end{array}$ & $\begin{array}{l}\text { Identify } \\
\text { the potential of } \\
\text { mobile crowdsourcing in soliciting informa- } \\
\text { tion on item prices } \\
\text { from the customers }\end{array}$ \\
\hline Question & Q8 & Do you have mobile phone/device? \\
\hline Metric & M1 & $\begin{array}{l}\text { Percentage of respondents who have mobile } \\
\text { phone/device }\end{array}$ \\
\hline Question & Q9 & $\begin{array}{l}\text { Can you access internet with your mobile } \\
\text { phone/device? }\end{array}$ \\
\hline Metric & M2 & Percentage of respondents who can access \\
\hline Question & Q10 & $\begin{array}{l}\text { Can you take photo using your mobile } \\
\text { phone/device? }\end{array}$ \\
\hline Metric & M3 & $\begin{array}{l}\text { Percentage of respondents who can take } \\
\text { photo }\end{array}$ \\
\hline Question & Q11 & $\begin{array}{l}\text { Do you bring your mobile phone/device } \\
\text { with you during your shopping trip? }\end{array}$ \\
\hline Metric & M4 & Percentage of respondents who bring \\
\hline Question & Q12 & $\begin{array}{l}\text { Do you have the time to use your mobile } \\
\text { phone/device while shopping? }\end{array}$ \\
\hline Metric & M5 & $\begin{array}{l}\text { Percentage of respondents who have the } \\
\text { time to access }\end{array}$ \\
\hline Question & Q13 & $\begin{array}{l}\text { How many hours in average that you usually } \\
\text { spend browsing the internet or accessing } \\
\text { mobile applications in a day? }\end{array}$ \\
\hline Metric & M6 & $\begin{array}{l}\text { Mod of total duration accessing the internet } \\
\text { and mobile applications }\end{array}$ \\
\hline Question & Q14 & $\begin{array}{l}\text { What is the subscription type of your mobile } \\
\text { phone/device? }\end{array}$ \\
\hline Metric & M7 & $\begin{array}{l}\text { Percentage of respondents who subscribe to } \\
\text { post-paid with mobile data plan }\end{array}$ \\
\hline Question & Q15 & $\begin{array}{l}\text { Do you face network problem (referring } \\
\text { to internet accessibility) when using your } \\
\text { mobile phone/device? }\end{array}$ \\
\hline Metric & M8 & $\begin{array}{l}\text { Percentage of respondents who face it oc- } \\
\text { casionally and less. }\end{array}$ \\
\hline Question & Q16 & $\begin{array}{l}\text { Do you share photos through your mobile } \\
\text { phone/device with others? }\end{array}$ \\
\hline Metric & M9 & Percentage who share. \\
\hline Question & Q17 & $\begin{array}{l}\text { If you find out that an item is cheaper than } \\
\text { its usual price, do you usually share about } \\
\text { it with your friends? }\end{array}$ \\
\hline Metric & M10 & Percentage who do \\
\hline Question & Q18 & $\begin{array}{l}\text { If you find out that an item is cheaper than } \\
\text { its usual price, do you think you should } \\
\text { share about it with your friends? }\end{array}$ \\
\hline Metric & M11 & Percentage who think they should \\
\hline
\end{tabular}

researchers. This was believed to be the result of the pilot testing performed earlier. For the online version of the questionnaire, invitations to participate were sent through emails and social media. The online version of the questionnaire was made accessible for the duration of one month. Since price hike is the issue that concerned everyone, we did not specify explicit criteria for the target population. Everyone who did grocery shopping was eligible to participate.

\section{RESUlts AND ANALYSis}

After the two research exhibitions and the one month period were over, a total of 138 responses was received, comprising $74(53.6 \%)$ hardcopy responses and $64(46.4 \%)$ online responses. Prior to the analysis, three hardcopy responses had to be excluded due to incomplete information. One question each from these responses was not answered. The results presented below are therefore based on 135 (97.8\%) valid responses. Due
TABLE III: Number of respondents after each branching

\begin{tabular}{llrr}
\cline { 2 - 4 } & Hardcopy & Online & Total \\
\hline Received responses & 74 & 64 & 138 \\
Valid responses & 71 & 64 & 135 \\
Proceed to Q9 & 71 & 64 & 135 \\
Proceed to Q10 & 70 & 62 & 132 \\
Proceed to Q16 & 67 & 62 & 129 \\
Proceed to Q11 and the rest & 70 & 62 & 132 \\
\hline
\end{tabular}

TABLE IV: Profiles for participants

\begin{tabular}{lrr}
\hline Characteristics & Frequency & Percentage \\
\hline Gender & & \\
Male & 51 & 37.78 \\
Female & 84 & 62.22 \\
Marital status & & \\
Single & 42 & 31.11 \\
Married & 93 & 68.89 \\
Income earner & & \\
Sole & 26 & 19.26 \\
$\quad$ Joint & 109 & 80.74 \\
Main breadwinner & 48 & 35.56 \\
Record expenses & 74 & 54.81 \\
\hline
\end{tabular}

to the branching questions, the number of analysed responses per question varies as shown in Table III. Descriptive statistics method was used in analysing the results obtained as listed in Table II.

\section{A. Demographics information}

From the total of 135 respondents, $84(62.22 \%)$ of them were females and $51(37.78 \%)$ were males as shown in Table IV. As can be seen from the table too, 93 (68.89\%) of the respondents were married and $42(31.11 \%)$ were not married. Demographics information then looked at the income and expenditure of the respondents. From the total of 135 respondents, only $26(19.26 \%)$ of them were the only income earner of the family as shown in Table IV. A significant majority of them $(80.74 \%)$ were not. From these, 48 (35.56\%) respondents were the main breadwinners of the household. This means that an additional 23 respondents who were not the only income earner of the household, were also the main breadwinner of the household. When asked whether or not they recorded their monthly expenditures, it was discovered that more than half of them $(54.81 \%)$ recorded their monthly expenditure, as also shown in Table IV.

With regard to the income range, 13 (9.63\%) of the respondents lived with the monthly income of less that RM1,200 as shown in Figure 2. RM1,200 was used specifically because this was the threshold value used by the government to identify low income earners. In other words, in Malaysia, household with income of RM1,200 or less is categorised as low income household [34] and hence qualifies for a number of benefits and initiatives offered by the government. The majority of the respondents $(54.07 \%)$ had household income between RM1,200 and RM8,000. There was also a notably large number of respondents $(36.30 \%)$ with household income of more than RM8,000. Household income is the combined income of the whole house, usually of husband and wife, 
Monthly household income range (Q6)

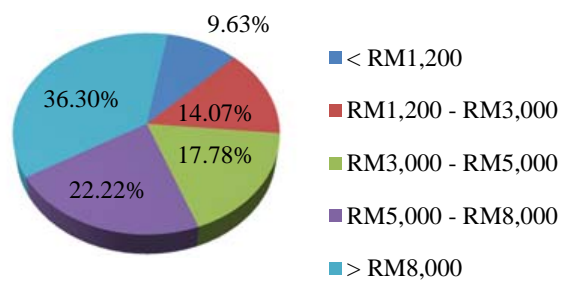

Fig. 2: Household income range of respondents

Average amount spent for household items per month (Q7)

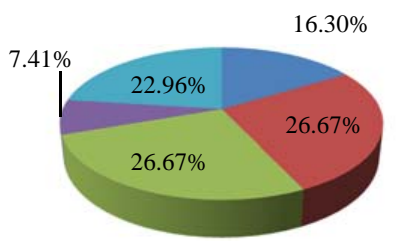

$$
\begin{aligned}
& \square<\mathrm{RM} 500 \\
& \square \mathrm{RM} 500-\mathrm{RM} 1,000 \\
& \square \mathrm{RM} 1,000-\mathrm{RM} 2,000 \\
& \square \mathrm{RM} 2,000-\mathrm{RM} 2,500 \\
& \square>\mathrm{RM} 2,000
\end{aligned}
$$

Fig. 3: Average amount spent on household items in a month

therefore, RM8,000 seems reasonable. The ceiling household income in our survey was capped at RM8,000, because this survey was part of the research that looks into ways to help the consumers cope with the increasing prices of items. Therefore, the focus was more on the low and middle income earners.

Finally, demographics information looked into the average monthly amount spent for household items. Results obtained showed that the majority (53.34\%) of the respondents spent between RM500 and RM2,000 for monthly household expenditure as presented in Figure 3. Only $22(16.30 \%)$ respondents spent less than RM500 per month on household expenditure. It is believed that this group of respondents came from those who were single and who were with lowest household income, although no effort was made to look into the results in detail with regard to this. A bubble plot of monthly household income versus average monthly household expenditure in Figure 4 shows that the household expenditure is proportional to the household income.

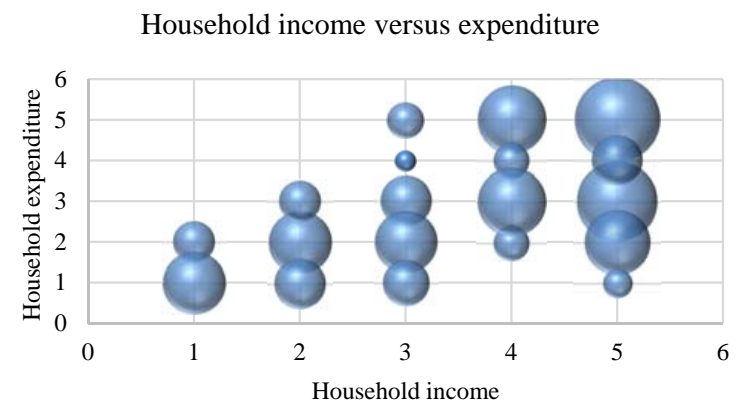

Fig. 4: Relationship between monthly income and expenses
TABLE V: Availability and capability of mobile devices

\begin{tabular}{lrr}
\hline Characteristics & Frequency & Percentage \\
\hline Devices availability & 135 & 100.00 \\
Internet accessibility & 131 & 97.04 \\
Photo taking feature & 132 & 97.73 \\
\hline
\end{tabular}

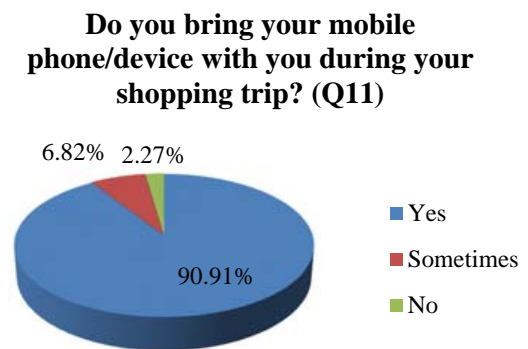

Fig. 5: Mobile phones availability during shopping trip

\section{B. Availability and capability of mobile devices}

With regard to the availability of mobile devices, it came as no surprise when the result showed that all participants (100\%) possessed mobile phone or devices as shown in Table V. We kind of expected this and the result confirmed our expectation. When asked whether the mobile devices that they have can be used to access the internet or not, 131 (97.04\%) of them were able to do that using their mobile devices. This represented a significant majority of the respondents. Noticeably, about the same percentage of respondents was found to be able to take photos using their mobile phone or devices as also shown in Table V.

\section{Pattern of mobile devices usage}

Next, the questionnaire explored about the pattern of mobile devices usage amongst the respondents, particularly during their shopping trips. It was found that $129(97.73 \%)$ respondents have their mobile devices with them during their shopping trips as shown in Figure 5. We further asked whether or not they are able to somehow use their mobile devices during the shopping trips and the result showed that 119 (91.54\%) of them were able to access their mobile devices while doing their shopping as shown in Figure 6.

The last question in this section asked about the daily average cumulative hours spent browsing the internet or ac-

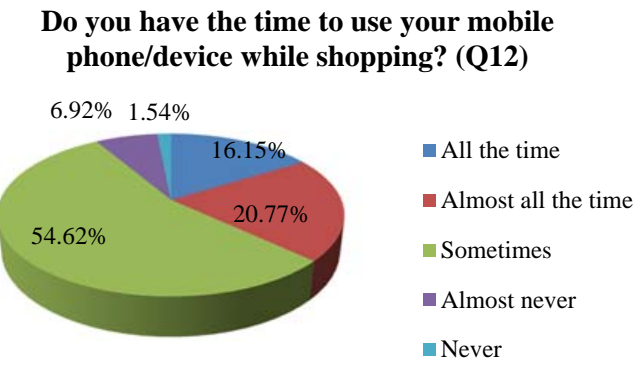

Fig. 6: Mobile phones accessibility during shopping trip 


\section{Average hours spent daily browsing the internet or accessing mobile applications (Q13)}

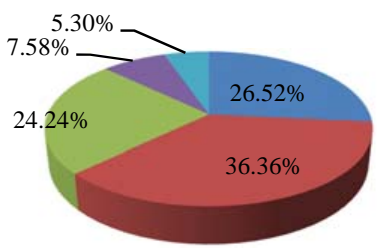

$$
\begin{aligned}
& \square<2 \text { hours } \\
& \square 2-4 \text { hours } \\
& -4-6 \text { hours } \\
& \square 6-8 \text { hours } \\
& \square>8 \text { hours }
\end{aligned}
$$

Fig. 7: Average hours spent daily using mobile phones to access the internet

TABLE VI: Types of mobile phone plan subscription

\begin{tabular}{ll}
\hline Types of subscription & Description \\
\hline Prepaid & $\begin{array}{l}\text { Subscribers can access the internet and mo- } \\
\text { bile application as long as they have avail- } \\
\text { able credit value. Credit value needs to be } \\
\text { topped up when it runs out. }\end{array}$ \\
Internet access is included in the subscribed \\
package. Users can access the internet con- \\
tinuously as long as the data limit is not \\
reached. Users will be billed at the end of \\
each month. \\
Package only covers phone call. Internet \\
access is not included. Users will have to \\
subscribe to the data plan on ad hoc basis \\
whenever needed.
\end{tabular}

cessing mobile applications. As can be seen from Figure 7, the majority of the respondents (68.18\%) spent between two and eight hours accessing the internet and mobile applications daily.

\section{Supporting infrastructure}

With regard to the supporting or enabling infrastructure, we first asked the respondents on the types of their mobile plan subscription. Generally, there are two types of subscription available in this country; prepaid and post-paid. Post-paid can be further categorised into post-paid with data plan and post-paid without data plan. Their differences with regard to internet accessibility is shown in Table VI.

As can be seen from the table, post-paid with data plan users will experience least disruption with their internet access. For this category of subscribers, internet accessibility will become a problem only when the bill is not paid and this is less likely to happen, compared with the other categories of subscribers. If the allocated data limit is reached, they can easily top it up and the cost will appear in the next bill. For post-paid with mobile data plan subscribers, the package enables them to access the internet and mobile applications, usually capped at certain data limit depending on the chosen plan. Subscription to this type of mobile plan enables them to experience uninterrupted internet access as long as the allocated limit is not exceeded. On the other hand, prepaid subscribers will have to ensure that their credit values are sufficient before they can use their line to access the internet.
What is the subscription type of your mobile phone/device? (Q14)

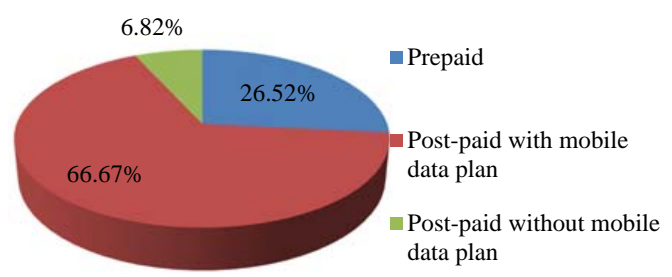

Fig. 8: Types of mobile phone plan subscription

\section{Do you face network problem when using your mobile phone/device? (Q15)}

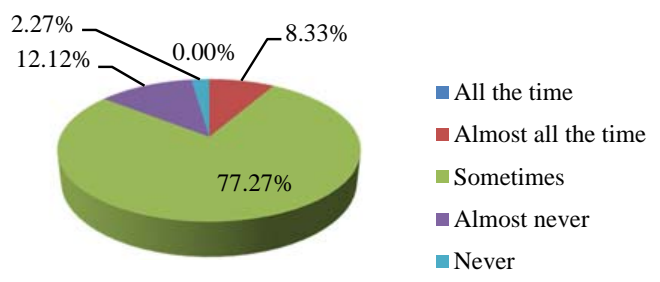

Fig. 9: Network availability

Based on the responses received, 88 (66.67\%) respondents are subscribed to post-paid with mobile data plan as shown in Figure 8.

The next question probed about their experience with the (mobile) network. Result showed that only 11 (8.33\%) respondents experienced network problem almost all of the time as shown in Figure 9. A vast majority of them (91.67\%) had no problem with the network. Intermittent and irregular interruptions in the network are expected and acceptable. It is beyond this research to investigate their causes, let alone to figure out ways to improve the situation.

\section{E. Readiness to share information}

The questionnaire eventually explored about the consumers readiness to share information by looking at their current practices and thought. With regard to their practice in photos sharing, $125(96.9 \%)$ respondents whose mobile devices had the capability to take photos had ever shared photos with others. Only that the frequency differs between all the time and hardly as shown in Figure 10.

When asked whether they were presently sharing information about prices of items with their friends whenever they found them cheaper than their usual prices, it was quite interesting and surprising at the same time to discover that $54(40.91 \%)$ of them firmly did so with an additional 65 (49.24\%) respondents occasionally did so as shown in Figure 11. Furthermore, regardless of whether they were presently sharing the information on prices of items with their friends or not, almost all of them (96.97\%) were positive about the idea as shown in Figure 12. 
Do you share photos through your mobile phone/device with others? (Q16)

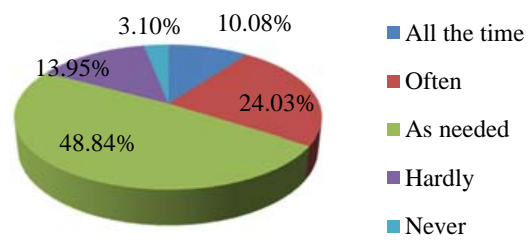

Fig. 10: Practice with regard to photo sharing

\section{If you find out that an item is cheaper than its usual price, do you usually share about it with your friends? (Q17)}

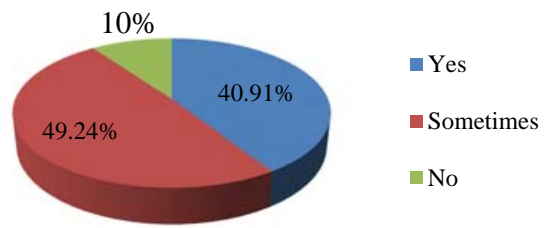

Fig. 11: Practice with regard to price information sharing

\section{Discussion}

The purpose of the survey was to quantitatively identify the potential of using mobile crowdsourcing to share information on prices of household items from the perspective of the consumers. Prior to analysing the collected data and coming out with the findings, we first looked at the relevance and reliability of the data. From the demographics information collected, it can be seen that the majority of the respondents are not the sole income earner of their family. Only 26 $(19.26 \%)$ of them are. Further analysis was also made to analyse the correlation between marital status and sole income earner status. It was found that from 93 respondents who are married, only $14(15.05 \%)$ of them are the sole income earner of their family. This means that for the majority of the respondents who are married $(68.89 \%)$, both husbands and wives are contributing to the household income. Further analysis also showed that only 37 of the respondents who are married, are also the main breadwinner of the household.

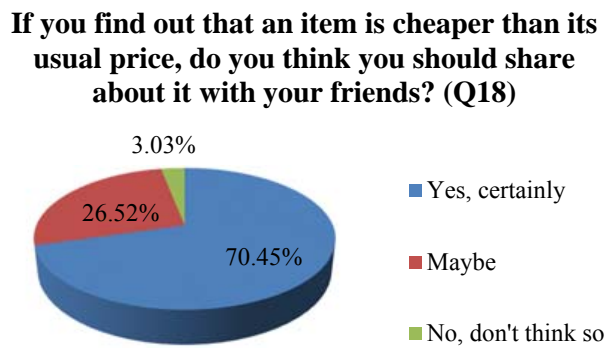

Fig. 12: Opinion on price information sharing
This can be inferred from the fact that the majority of the respondents are female $(62.22 \%)$ and the majority of the married respondents, 60 out of $93(64.52 \%)$, are also female. By convention, husbands are the main breadwinners of the households, although not necessarily. Although the majority of the respondents are female and are not the sole income earner or main breadwinner of their households, the data also show that both equally contribute to the household income and hence, manage the expenditures. Therefore, they have the required knowledge to answer the questions and subsequently provide reliable data. Furthermore, the majority of the respondents $(54.8 \%)$ do record their monthly expenditures, which further strengthen the reliability of the collected data. Additionally, from the bubble plot in Figure 4, a monotonic correlation pattern can be seen between household income amount and household expenditure amount, with a few exclusions of those who gain most but spend least. The monotonic relationship is further supported by means of Spearman rank order correlation test that yields a $\mathrm{p}$ value of 0.9993 , which indicates strong positive correlation between the two. This implies their normal and wise spending behaviour.

\section{A. Ubiquity of mobile devices}

In order to determine the potential use of mobile crowdsourcing in information sharing of prices of items from the perspective of mobile device capability, we first looked at the availability of the mobile devices. Though it may be obvious to some that mobile device is something that everybody has, it is better to have empirical data that can support the claim. As can be seen from the result shown in Table V, all of the survey respondents have mobile phones or devices and almost all of the respondents who have mobile phones or devices are able to access the internet using their mobile phones or devices. Furthermore, almost all of those who can access the internet using their mobile phones or devices are able to take photos with their mobile phones or devices. In order for the mobile crowdsourcing to be successfully used in sharing of information on prices of items, it is important for the potential users to have mobile phones or devices which features enable them to access the internet and take photos of the shared items and with respect to this perspective, it can be concluded that the potential use of mobile crowdsourcing in information sharing of items prices is high.

\section{B. Internet as part and parcel of lifestyle}

The second perspective investigates the pattern of mobile phones or devices usage. Having the required mobile phones or devices alone is not sufficient if their usage pattern is not in support of the requirements of the mobile application that will be developed for the purpose of sharing of information on prices of items. Results show that a large majority of the respondents do bring their mobile phones or devices with them during their shopping trips and almost all of the respondents are able to use the phone during their shopping trips although with varying chances. Amongst the aims of the use of mobile crowdsourcing in information sharing of prices is to enable 
timely sharing of information [9]. For this, immediate update of information is expected, which means that it will be best if they can update the information during the shopping trips. Furthermore, result from the survey also showed that the majority of the respondents spend more than two hours daily accessing the internet, which is regarded as sufficient for them to use the mobile applications developed for the purpose of sharing the items prices information. The fact that the majority of the respondents spend more than two hours on average accessing the internet and mobile applications also implies their familiarity with mobile applications. Hence, it is not foreseen as a problem to use yet another mobile application that can help them in reducing their monthly expenditures. Since a large majority of them do bring the mobile phones or devices with them during their shopping trips and are able to access them during the trips, and that their usage pattern is also in support of the use of mobile applications, it can be concluded that the potential use of mobile crowdsourcing in information sharing of items prices with regard to this perspective is also high. This finding confirms the informal observation and assumption on the prevalence of mobile devices that are often not backed by statistical data.

\section{Continuous internet accessibility}

Next, we also looked at the potential of using crowdsourcing in information sharing of items prices from the perspective of the enabling infrastructure. Results showed that with regard to the network connectivity, the majority of the respondents are experiencing smooth network connectivity with problems occurring only occasionally. From this perspective, we also probed on the types of plan that that they are currently subscribed to. Based on the result shown in Figure 8, the majority of the respondents belong to this category of subscribers, which implies that the majority of them experience least internet access disruption. Therefore, from the perspective of enabling infrastructure, we can also conclude that the potential of mobile crowdsourcing in information solicitation and sharing of items prices is also high.

\section{Positive attitude toward information sharing}

Finally, we identify the potential of using mobile crowdsourcing for information sharing of items prices by looking at the current practice of the respondents and their opinion about information sharing of items prices, which constitute the fourth perspective; readiness to share the information. From the survey, it was discovered that the majority of the respondents are used to sharing photos with their friends albeit with differing frequency. Only $3.10 \%$ of them who had never shared. In sharing information on prices of items, it is expected that the photos of the items need to be shared as well if the photos have never been uploaded onto the application. If they are already used to sharing photos with others, they will not be facing any problem to do the same when sharing information on items prices with others. It was also quite surprising to discover that the majority of the respondents are also presently sharing the information on items prices with their friends despite the absence of a proper mechanism or application to do that. Only $10 \%$ of the respondents did not share the information and interestingly, $70 \%$ of respondents who are not currently sharing the information agree that they should share. Therefore, it can be concluded that from the perspective of the readiness to share information on prices of items, the potential is also high. Their mindset is more than ready to share the information on items prices.

Given that findings from all perspectives are positively supporting the potential of using mobile crowdsourcing in information solicitation and sharing of items prices, it can be concluded that based on the data collected from the survey, the potential of using mobile crowdsourcing in information solicitation and sharing on prices of items is high.

\section{ThreATS TO VALIDITY}

While every care has been taken to ensure the reliability of the information gathered, its representativeness cannot be totally guaranteed as the data are obtained from sampled population. However, the following measures have been taken to mitigate the possible threats to data validity. On construct validity, a pilot test was performed prior to the actual questionnaire distribution to ensure that the potential respondents share common understanding of the questions in the questionnaire. As a result, a number of questionnaires were rearranged and rephrased for clarity. One question was also removed. Furthermore, there was no technical jargons or terms in the questionnaire that are difficult to understand and may cause misunderstanding. On external validity, as explained earlier, the questionnaires were distributed at research exhibitions that were open to public visitors. There was also the online version of the questionnaire that was able to reach respondents from various backgrounds. On internal validity, as can be seen in this article, only basic descriptive statistics are used in analysing the results, which are derived directly from the raw data gathered. Finally, on reliability, detailed descriptions on the survey method and questionnaire structure have been included to enable replication of the study.

\section{CONCLUSION}

This article presents the results of a survey performed that explored the potential of using mobile crowdsourcing as means to share information on prices of items. The purpose of sharing prices information is to enable consumers to perform convenient and timely comparison of household items prices. The means being able to do so at the comfort of their house but getting up-to-date information. The comparison is necessary due to the ever increasing prices of items that has directly contributed to the overall increase in the cost of living. Findings from the analyses showed that the potential of using mobile crowdsourcing to solicit and share the information is high, with all four perspectives that determined the potential returned positive findings. Future research work will focus on the development of a model to realise the information sharing of prices through mobile crowdsourcing, which is expected to be able to help people to save on their household expenditures 
despite the continuous price hike. Findings from this research contributes to the broader community in mobile crowdsourcing research for consumers as they are backed by data collected from the actual consumers. With the confirmed potential, more research opportunities should be explored that will bring more benefits and convenience to the users.

\section{ACKNOWLEDGEMENT}

Information presented in this paper constitutes a part of the research titled The Construction of a Pricewatch Information Solicitation and Sharing Model for Timely Price Comparison of Household Products using Mobile Crowdsourcing (FRGS/1/2014/SS07/UNITEN/02/1) funded by the Ministry of Higher Education Malaysia.

\section{REFERENCES}

[1] Department of statistics malaysia. http://www.statistics.gov.my/portal/ index.php?option=com_content $\&$ view $=$ article $\&$ id $=767 \&$ Itemid $=111 \&$ lang=en\#2, Accessed on 10th July 2014.

[2] Pdrm mydistress rescue doctrine application. http://mydistress.net/main/ app/mydistress.

[3] Singapore consumer price index. http://www.singstat.gov.sg/news/press_ releases/cpifeb2014.pdf, Accessed on 10th July 2014.

[4] Callaghan innovation, 2014. http://callaghaninnovation.govt.nz.

[5] E. Akhir, Y. Chen, G. K. Nee, S. Sugathan, and S. Obama, "Information sharing through football website - Equatorial Guinea (EG) case study", in Information Technology (ITSim), 2010 International Symposium in, volume 3, pp. 1576-1580, June 2010.

[6] S. L. Alam and J. Campbell, "A conceptual framework of influences on a non-profit GLAM crowdsourcing initiative: A socio-technical perspective", in 24th Australasian Conference on Information Systems, ACIS 2013, dec 2013.

[7] N. Almadhoun, P. Dominic, and L. F. Woon, "Perceived security, privacy, and trust concerns within Social Networking Sites: The role of Information sharing and relationships development in the Malaysian Higher Education Institutions' marketing", in Control System, Computing and Engineering (ICCSCE), 2011 IEEE International Conference on, pp. 426-431, Nov 2011.

[8] H. Aris, "Local Pricewatch Information Solicitation and Sharing Model using Mobile Crowdsourcing", in 1st International Conference on Communication and Computer Engineering, pp. 449-457, 2014.

[9] H. Aris and M. Md Din, "On Using Mobile Crowdsourcing for Timely Information Solicitation and Sharing of Prices", in Proceedings of the 9th International Conference on Software Engineering and Applications, ICSOFT-EA 2014, pp. 518-523. SCITEPRESS, 2014.

[10] D. C. Brabham, K. M. Ribisl, T. R. Kirchner, and J. M. Bernhardt, "Crowdsourcing Applications for Public Health", Am. J. Prev. Med., 46(2):179-187, 2014.

[11] J. Brownstein. Healthmap: Outbreaks near me, 2014. https://itunes. apple.com/us/app/healthmap-outbreaks-near-me/id328358693?mt=8, Accessed on 24/6/2014.

[12] K. M. Calo, K. Cenci, P. Fillottrani, and E. Estevez, "Information sharing-benefits", J. Comput. Sci. Tech., pp. 49-55, 2012.

[13] V. Chanal and M.-L. Caron-Fasan, "How to invent a new business model based on crowdsourcing : the Crowdspirit case", in Conférence de l'Association Internationale de Management Stratégique, pp. 1-27, Sophia-Antipolis, France, May 2008.

[14] E. Chu, Y.-L. Chen, J.-Y. Lin, and J. Liu, "Crowdsourcing support system for disaster surveillance and response", in Wireless Personal Multimedia Communications (WPMC), 2012 15th International Symposium on, pp. 21-25, Sept 2012.

[15] H.-M. Chuang and C.-C. Shen, "A study on the applications of information-sharing concepts to the teaching in elementary school", in Machine Learning and Cybernetics, 2008 International Conference on, volume 1, pp. 174-179, July 2008.

[16] N. Eagle. "Internationalization, Design and Global Development: Third International Conference, IDGD 2009, Held as Part of HCI International 2009, San Diego, CA, USA, July 19-24, 2009. Proceedings", chapter txteagle: Mobile Crowdsourcing, pp. 447-456. Springer Berlin Heidelberg, Berlin, Heidelberg, 2009.
[17] E. Estellés-Arolas and F. González-Ladrón-de Guevara, "Towards an integrated crowdsourcing definition”, J. Inform. Sci., 38(2):189-200, 2012.

[18] A. Foncubierta Rodríguez and H. Müller, "Ground Truth Generation in Medical Imaging: A Crowdsourcing-based Iterative Approach", in Proceedings of the ACM Multimedia 2012 Workshop on Crowdsourcing for Multimedia, CrowdMM '12, pp. 9-14, New York, NY, USA, 2012. ACM.

[19] P. Fraternali, A. Castelletti, R. Soncini-Sessa, C. V. Ruiz, and A. Rizzoli, "Putting humans in the loop: Social computing for Water Resources Management", Eviron. Modell. Softw., 37:68-77, 2012. Environmental Modelling Software.

[20] F. Fuchs-Kittowski and D. Faust. Architecture of mobile crowdsourcing systems. in N. Baloian, F. Burstein, H. Ogata, F. Santoro, and G. Zurita, editors, Collaboration and Technology, volume 8658 of Lecture Notes in Computer Science, pp. 121-136. Springer International Publishing, 2014.

[21] H. Gao, G. Barbier, and R. Goolsby, "Harnessing the Crowdsourcing Power of Social Media for Disaster Relief", IEEE Intell. Syst., 26(3):1014, 2011.

[22] M. F. Goodchild and J. A. Glennon, "Crowdsourcing geographic information for disaster response: a research frontier", Int. J. Digit. Earth, 3(3):231-241, 2010.

[23] Healthmap. Contagious disease surveillance and virus awareness, 2014 http://healthmap.org.

[24] J. Heinzelman, R. Brown, and P. Meier, "Mobile Technology, Crowdsourcing and Peace Mapping: New Theory and Applications for Conflict Management", pp. 39-53, 2011.

[25] J. Howe, "The Rise of Crowdsourcing", Wired Magazine, 14(6), 2006.

[26] J. M. Leimeister. Crowdsourcing as a new way of organizing work.

[27] P. Marshall, R. Cain, and S. R. Payne, "Situated crowdsourcing: a pragmatic approach to encouraging participation in healthcare design", Pervasive Computing Technologies for Healthcare (PervasiveHealth), 2011, pp. 555-558, 2011.

[28] A. McCoy, D. Sittig, and A. Wright, "Comparison of Association Rule Mining and Crowdsourcing for Automated Generation of a ProblemMedication Knowledge Base", in Healthcare Informatics, Imaging and Systems Biology (HISB), 2012 IEEE Second International Conference on, pp. 125-125, Sept 2012.

[29] D. McKinley. Non-profit crowdsourcing, 2015. http://nonprofitcrowd. org/crowdsourcing/.

[30] J. Mtsweni and L. Burge, "The potential benefits of mobile microwork services in developing nations: Research opportunities and challenges", in IST-Africa Conference Proceedings, 2014, pp. 1-10, May 2014.

[31] U. B. of Labor Statistics'. Consumer expenditures in 2012. Technical report, US Bureau of Labor Statistics, 2014.

[32] StatPac. Qualitites of a good question. http://www.statpac.com/surveys/ question-qualities.htm, accessed on 5th July 2014.

[33] H. Väätäjä, T. Vainio, and E. Sirkkunen, "Location-based Crowdsourcing of Hyperlocal News: Dimensions of Participation Preferences", in Proceedings of the 17th ACM International Conference on Supporting Group Work, GROUP '12, pp. 85-94, New York, NY, USA, 2012. ACM.

[34] W. M. Vagias. Likert-type scale response anchors. https://www. clemson.edu/centers-institutes/tourism/documents/sample-scales.pdf, Clemson International Institute for Tourism \& Research Development, Department of Parks, Recreation and Tourism Management. Clemson University.

[35] R. van Solingen, V. Basili, G. Caldiera, and H. D. Rombach. "Goal Question Metric (GQM) Approach". John Wiley Sons, Inc., 2002.

[36] S. N. Wan-Ahmad-Makki-Mashor. Dbkl akan wujud aplikasi harga barangan (press cutting). http://www.hmetro.com.my/articles/ DBKLakanwujudaplikasihargabarangan/Article/, Accessed on 10th July 2014.

[37] S. Wang, J. Chen, and F. Xie, "Intermediating R\&D and marketing value creation by open innovation", in 2011 IEEE International Conference on Industrial Engineering and Engineering Management, pp. 1170-1174. IEEE, 2011.

[38] P. Whitla, "Crowdsourcing and Its Application in Marketing Activities", Contemporary Management Research CMR, 5(1):1628, 2009.

[39] B. Yu, M. Willis, P. Sun, and J. Wang, "Crowdsourcing Participatory Evaluation of Medical Pictograms Using Amazon Mechanical Turk", J. Med. Internet Res., 15(6), Mar 2013. 